\title{
Influência de fontes e modos de aplicação de nitrogênio nos componentes da produção e produtividade do milho irrigado no cerrado
}

\author{
Amanda Failli Schiavinatti ( $\left.{ }^{1}\right)$; Marcelo Andreotti $\left({ }^{1 *}\right)$; Cleiton Gredson Sabin Benett ( $\left.{ }^{2}\right)$; Cristiano \\ Magalhães Pariz ('); Bruno Nascimento Lodo ('); Salatiér Buzetti (') \\ (') Universidade Estadual Paulista, Faculdade de Engenharia, Departamento de Fitossanidade, Engenharia Rural e Solos. Caixa \\ Postal 31, 15385-000 Ilha Solteira (SP), Brasil. \\ (2) Universidade Estadual do Mato Grosso do Sul, Departamento de Agronomia. Rodovia Aquidauana/UEMS, km 12, $79200-000$ \\ Aquidauana (MS), Brasil. \\ (*) Autor correspondente: sbuzetti@agr.feis.unesp.br
}

Recebido: 16/ago./2010; Aceito: 26/ago./2011

\begin{abstract}
Resumo
O objetivo do trabalho foi comparar os efeitos de fontes nitrogenadas: sulfonitrato de amônio com inibidor de nitrificação, sulfato de amônio e uréia, aplicadas na semeadura e/ou em cobertura, sobre teores de $\mathrm{N}$ foliar e clorofila, componentes da produção e produtividade do milho no verão, na região de cerrado sob irrigação. O trabalho foi desenvolvido em Latossolo Vermelho Distroférrico, nos anos agrícolas de 2006/2007 e 2007/2008. O delineamento experimental utilizado foi em blocos casualizados com quatro repetições, em esquema fatorial 3×5, sendo: três fontes de nitrogênio aplicadas na semeadura e/ou em cobertura, no estádio de 8 folhas completamente desdobradas, em 5 modos de aplicação $(0+120 ; 30+90 ; 60$ + 60; 90 + 30 e 120 + 0 kg ha ${ }^{-1}$ de N). O sulfonitrato de amônio + inibidor de nitrificação difere em relação ao sulfato de amônio quantos aos componentes da produção do milho cultivado no verão, independentemente da época de aplicação. A aplicação de $120 \mathrm{~kg} \mathrm{ha}^{-1}$ de nitrogênio usando a uréia em aplicação única no estádio de oito folhas na cultura do milho e em períodos com alta precipitação pluvial afeta negativamente os teores foliares de $\mathrm{N}$ no milho e resulta em menor produtividade de grãos em relação à aplicação da mesma dose na semeadura.
\end{abstract}

Palavras-chave: Zea mays, sulfonitrato de amônio, sulfato de amônio e uréia.

\section{Influence of nitrogen sources and application methods on yield and productivity components of irrigated corn in savannah soil}

\footnotetext{
Abstract

The objective of this experiment was to compare the effect of nitrogen sources: ammonium sulfonitrate with nitrification inhibitor, ammonium sulfate and urea, applied at sowing and/or as side dressing) on the leaf content of $\mathrm{N}$ and chlorophyll content, yield and production components of corn grown in savannah soil, under sprinkler irrigation. The research was carried out on Oxisol, during crop years of 2006/2007 and 2007/2008. The experimental design was the randomized blocks with four replications, in a $3 \times 5$ factorial outline consisting of: three nitrogen sources applied at sowing and/or side dressing at the 8 unfolded-leaf stage, in five different application ways $(0+120 ; 30+90 ; 60+60 ; 90+30$ and $120+0$ kg ha-1 of N). The application of sulphonitrate ammonium + inhibitor was similar to ammonium sulfate on the corn yield components, regardless of time of application. The application of $120 \mathrm{~kg} \mathrm{ha}^{-1}$ of $\mathrm{N}$ as urea in a single application at the stage of eight leaves in corn and in periods with high precipitation affects negatively the foliar $\mathrm{N}$ content and results in less grain yield in relation to the application of the same dose at sowing.
}

Key words: Zea mays, ammonium sulfonitrate, ammonium sulfate and urea. 


\section{INTRODUÇÃO}

O milho é uma cultura de importância econômica e devido ao valor nutricional de seus grãos, é utilizado na alimentação humana, animal e em matérias-primas na indústria.

A produtividade de grãos de milho é influenciada pela disponibilidade de nitrogênio no solo durante o ciclo de desenvolvimento da planta, como constataram Bortolini et al. (2001), ao enfatizar que este elemento é o que, frequentemente, mais limita a produtividade de grãos de milho, mas também proporciona as maiores produtividades da cultura. Este fato ocorre pela importância no metabolismo das plantas, com reflexos na produtividade, posto que a cultura é exigente, em média, de $23,8 \mathrm{~kg}$ de $\mathrm{N}$ para cada tonelada de grãos (Duete et al., 2008).

$\mathrm{O}$ nitrogênio, em funçấo de suas transformações no solo, tem proporcionado resultados divergentes em relação à sua época de aplicação (SouzA et al., 2001). Assim, o parcelamento e a escolha da época de aplicaçáo do adubo nitrogenado constituem-se em alternativas para aumentar a eficiência de uso da adubação nitrogenada pela cultura do milho e mitigar as perdas. Isso é respaldado pelo maior aproveitamento do $\mathrm{N}$, resultante da sincronização entre as aplicaçóes e o período de alta demanda do nutriente (Amado et al., 2002; SiLva et al., 2005a).

VITTI et al. (2002) observaram que a fonte de nitrogênio a ser utilizada é de suma importância, uma vez que as respostas das culturas às fontes de nitrogênio podem ser atribuídas a outros fatores à adição do enxofre e às alterações no pH do solo. Também, Amado et al. (2000), verificaram que em condições favoráveis à cultura do milho, a quantidade requerida para otimizar a produção de grãos pode alcançar valores superiores a $150 \mathrm{~kg} \mathrm{ha}^{-1}$.

O nítrico amoniacal sulfonitrato de amônio, com inibidor de nitrificação é um fertilizante de uso recente no Brasil, sendo composto pela mistura de nitrato de amônio + sulfato de amônio, que possui $26 \%$ de $\mathrm{N}$ total, em sua maior parte na forma amoniacal $(18,5 \%$ amoniacal e $7,5 \%$ na forma nítrica) e $12 \%$ de enxofre, com moléculas DMPP (3,4 dimetilpirazolfosfato) para inibir o processo rápido da nitrificação. O sulfato de amônio e a uréia são os fertilizantes nitrogenados mais utilizados e que em determinadas condições podem ter menor eficácia, devido principalmente às perdas por volatilização da amônia. Portanto, o objetivo deste trabalho foi comparar os efeitos de fontes de nitrogênio aplicadas na semeadura e/ou em cobertura, sobre os componentes de produção e na produtividade da cultura do milho irrigado na regiáo de cerrado.

\section{MATERIAL E MÉTODOS}

O estudo foi desenvolvido em uma área sob sistema de plantio direto (SPD) no município de Selvíria (MS). O solo da área experimental foi classificado como Latossolo Vermelho
Distroférrico e com histórico em SPD de quatro anos com culturas anuais (feijão, milho, trigo), tendo sido cultivada com o milho safrinha no início do ano de 2006. As características químicas do solo foram determinadas antes da instalação do experimento, segundo método proposto por RaIj et al. (2001), com os seguintes atributos avaliados na camada de 0,0 a $0,20 \mathrm{~m}: \mathrm{P}$ (resina) $=31 \mathrm{mg} \mathrm{dm}^{-3}$, $\mathrm{M} . \mathrm{O}=34 \mathrm{~g} \mathrm{dm}^{-3}, \mathrm{pH} \mathrm{CaCl}=5,0, \mathrm{~K}, \mathrm{Ca}, \mathrm{Mg}, \mathrm{H}+\mathrm{Al}$ e CTC $=4,3 ; 19,12,40$ e $55,5 \mathrm{mmol}_{c} \mathrm{dm}^{-3}$, respectivamente, bem como teor de argila de $630 \mathrm{~g} \mathrm{~kg}^{-1}$, de silte de $80 \mathrm{~g} \mathrm{~kg}^{-1}$ e de areia de $290 \mathrm{~g} \mathrm{~kg}^{-1}$. Os dados climáticos referentes ao período de desenvolvimento do trabalho estão relacionados na figura 1 .

$\mathrm{O}$ experimento foi desenvolvido em área irrigada por aspersão (pivô central) e a semeadura realizada mecanicamente em 24/10/2006 (primeiro cultivo) e 25/10/2007 (segundo cultivo), visando à população de 60.000 plantas ha ${ }^{-1}$. $\mathrm{Na}$ adubação de semeadura foram aplicados, manualmente, no sulco, 90 e $30 \mathrm{~kg} \mathrm{ha}^{-1}$ de $\mathrm{P}_{2} \mathrm{O}_{5}$ e $\mathrm{K}_{2} \mathrm{O}$, na forma de superfosfato simples $\left(18 \% \mathrm{P}_{2} \mathrm{O}_{5}\right)$ e cloreto de potássio $\left(60 \% \mathrm{~K}_{2} \mathrm{O}\right)$ respectivamente. A determinação da dose de cada nutriente baseou-se nos resultados da análise do solo do experimento e na tabela de recomendação de adubação para a cultura do milho, para o Estado de São Paulo, conforme descrito em RaIj et al. (1997). A cultivar de milho utilizada foi o híbrido simples Dow 2B710.

O delineamento experimental utilizado foi o de blocos casualizados, com 15 tratamentos e quatro repetiçôes, dispostos em: esquema fatorial $3 \times 5$, sendo três fontes de nitrogênio sulfonitrato de amônio com inibidor de nitrificação (SNA+DMPP), sulfato de amônio (SA) e uréia (U) aplicadas na semeadura e/ou em cobertura, no estádio de

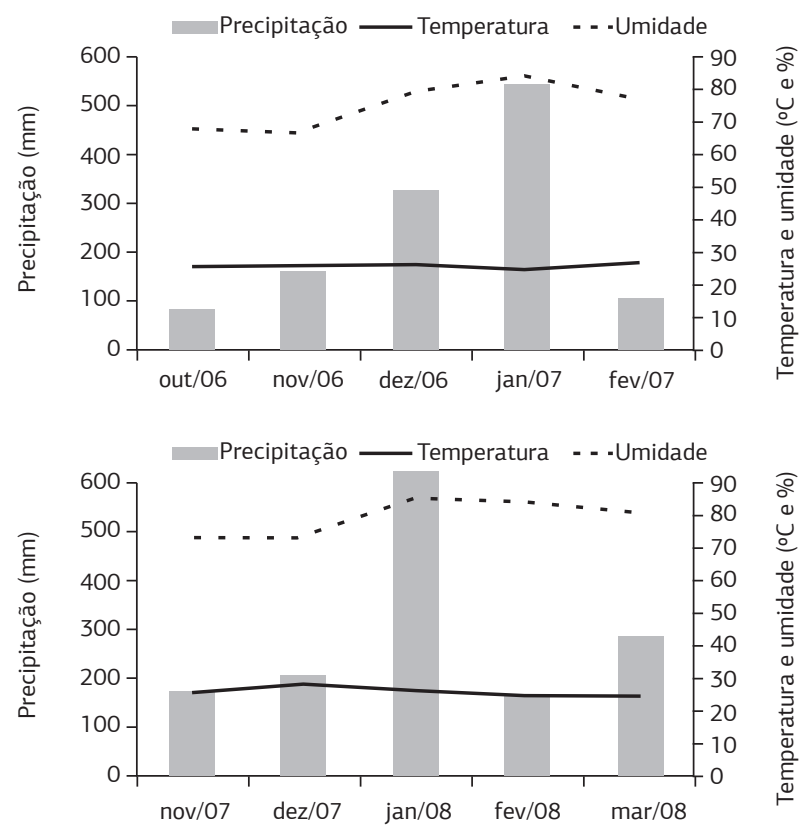

Figura 1. Precipitação pluvial mensal e médias da temperatura e umidade relativa do ar durante os dois ciclos de cultivo. 
oito folhas completamente desdobradas (linha de união lâmina-bainha, "colar" visível), em cinco modos de aplicação $\left(0+120 ; 30+90 ; 60+60 ; 90+30\right.$ e $\left.120+0 \mathrm{~kg} \mathrm{ha}^{-1} \mathrm{de} \mathrm{N}\right)$ nos anos agrícolas de 2006/2007 e 2007/2008 com quatro repetiçóes. Cada parcela experimental foi composta por seis linhas de $7 \mathrm{~m}$ de comprimento, espaçadas $0,90 \mathrm{~m}$ entre si, e as duas linhas externas consideradas bordaduras, sendo consideradas para as avaliaçôes apenas as quatro linhas internas; por ocasião das avaliaçôes e da colheita, descartouse $1 \mathrm{~m}$ de cada extremidade das linhas internas. $\mathrm{Na}$ área experimental, o fornecimento de água foi efetuado de três em três dias de acordo com as necessidades das plantas, por meio de um sistema de irrigaçáo do tipo pivô central.

Para adubaçáo de cobertura, o adubo foi posicionado na entrelinha, a uma distância de aproximadamente 0,20 m do colmo das plantas de milho. Logo após a distribuição do adubo, foi realizada irrigação das parcelas.

Os atributos avaliados foram: populaçáo final de plantas $\mathrm{ha}^{-1}$, número de espigas ha ${ }^{-1}$, altura de plantas, altura de inserção da espiga principal, diâmetro basal do colmo, teor de $\mathrm{N}$ foliar, leituras SPAD nas folhas usando clorofilômetro (SPAD-502), no florescimento, número médio de fileiras de grãos por espiga, número médio de grãos por fileiras, número médio de grãos por espiga, massa de cem grãos e produtividade de grãos ( $13 \%$ de umidade).

Os dados obtidos foram submetidos à análise de variância (teste $\mathrm{F}$ ), sendo as médias comparadas pelo teste Tukey a $5 \%$ de probabilidade. As análises estatísticas foram processadas utilizando o programa de Análise Estatística - SISVAR.

\section{RESULTADOS E DISCUSSÃO}

Avaliando os resultados contidos nas tabelas 1 e 2, verifica-se que não houve efeito de fontes e modos de aplicação do nitrogênio para a população de plantas, número de espigas $\mathrm{ha}^{-1}$, altura média da plantas, altura de inserção da espiga principal, número de fileiras de grãos por espiga e teor de N foliar, em 2006/2007 e 2007/2008 e leitura SPAD somente para 2006/2007. O mesmo foi observado por Casagrande e Fornasieri Filho (2002) que não verificaram diferenças significativas da época de aplicação do $\mathrm{N}$ (todo na semeadura ou todo em cobertura) e de doses de $\mathrm{N}$ nas características agronômicas do milho safrinha.

FERnANDes et al. (2005) não constataram efeito significativo das doses $\left(0,30,90\right.$ e $\left.180 \mathrm{~kg} \mathrm{ha}^{-1} \mathrm{de} \mathrm{N}\right)$ para o número de fileiras de grãos por espiga e Oliveira e CaIres (2003), avaliando doses e modos de aplicaçáo das fontes de $\mathrm{N}$, também não verificaram efeito significativo para a altura de plantas de milho e altura de inserção da espiga. Possamai et al. (2001), avaliando sistemas de preparo de solo, observaram que em plantas com a inserçáo mais alta de espiga, havia vantagem na colheita mecanizada, por resultar em menor perda de espigas nessa operaçáo, fato não avaliado neste trabalho.

Entretanto, o diâmetro basal do colmo foi influenciado significativamente pelo modo de aplicação de $\mathrm{N}$, em que as maiores quantidades de $\mathrm{N}$ fornecidas na semeadura proporcionaram maior diâmetro (Tabela 2). As maiores doses de $\mathrm{N}$ fornecidas em cobertura resultaram em colmos mais finos, uma vez que na fase de crescimento vegetativo há maior demanda do elemento para produção de tecidos na planta.

Para as fontes de nitrogênio não houve resposta no diâmetro basal do colmo. De modo geral, estes resultados assemelham-se aos verificados por Meira (2006), que relacionou a ausência de resposta de diferentes fontes (SNA + DMPP, AS e U) ao fato de ter sido efetuada a irrigação das parcelas logo após as aplicaçōes, reduzindo possíveis perdas por volatilização, principalmente da uréia. Neste caso, sem o problema da volatilização da amônia, proveniente da uréia,

Tabela 1. Médias de população de plantas (PP), número de espigas (NE), altura de plantas (ALT), altura de inserção da espiga principal (AIEP) em função de fontes e modos de aplicação de $\mathrm{N}$ na cultura do milho irrigado

\begin{tabular}{|c|c|c|c|c|c|c|c|c|}
\hline \multirow{4}{*}{ Tratamentos } & \multicolumn{8}{|c|}{ Ano Agrícola } \\
\hline & 2006/ & 2007/ & 2006/ & 2007/ & 2006/ & 2007/ & 2006/ & 2007/ \\
\hline & 2007 & 2008 & $2007^{*}$ & 2008 & 2007 & & & \\
\hline & \multicolumn{2}{|c|}{$\begin{array}{c}\text { PP } \\
(\text { planta ha-1) }\end{array}$} & \multicolumn{2}{|c|}{$\begin{array}{c}\text { NE } \\
(\text { espigas ha-1) }\end{array}$} & \multicolumn{2}{|c|}{$\begin{array}{l}\text { ALT } \\
(\mathrm{m})\end{array}$} & \multicolumn{2}{|c|}{$\begin{array}{l}\text { AIEP } \\
(\mathrm{m})\end{array}$} \\
\hline \multicolumn{9}{|l|}{ Fontes } \\
\hline SA & $51.444 \mathrm{a}$ & $61.889 a$ & $51.444 \mathrm{a}$ & $60.667 \mathrm{a}$ & $2,36 \mathrm{a}$ & $2,72 \mathrm{a}$ & $1,07 \mathrm{a}$ & $1,18 \mathrm{a}$ \\
\hline Uréia & $52.111 \mathrm{a}$ & $58.667 \mathrm{a}$ & $50.555 \mathrm{a}$ & $58.333 \mathrm{a}$ & $2,34 \mathrm{a}$ & $2,73 \mathrm{a}$ & $1,06 \mathrm{a}$ & $1,17 \mathrm{a}$ \\
\hline \multicolumn{9}{|l|}{ Modos } \\
\hline $120+0$ & $52.963 \mathrm{a}$ & $58.148 \mathrm{a}$ & $51.481 \mathrm{a}$ & $56.667 \mathrm{a}$ & $2,34 \mathrm{a}$ & $2,76 \mathrm{a}$ & 1,07 a & $1,21 \mathrm{a}$ \\
\hline $30+90$ & $50.185 \mathrm{a}$ & $58.889 a$ & $50.741 \mathrm{a}$ & $57.037 \mathrm{a}$ & $2,37 \mathrm{a}$ & $2,70 \mathrm{a}$ & $1,07 \mathrm{a}$ & $1,15 \mathrm{a}$ \\
\hline $60+60$ & $51.852 \mathrm{a}$ & $62.222 \mathrm{a}$ & $51.296 \mathrm{a}$ & $61.296 \mathrm{a}$ & $2,36 \mathrm{a}$ & $2,77 \mathrm{a}$ & $1,06 \mathrm{a}$ & $1,21 \mathrm{a}$ \\
\hline $0+120$ & $52.963 \mathrm{a}$ & $62.777 \mathrm{a}$ & $52.037 \mathrm{a}$ & $62.222 \mathrm{a}$ & $2,38 \mathrm{a}$ & $2,68 \mathrm{a}$ & 1,07 a & $1,14 \mathrm{a}$ \\
\hline CV (\%) & 7,31 & 11,20 & 8,90 & 10,20 & 2,50 & 3,50 & 3,97 & 5,80 \\
\hline
\end{tabular}

* Interação fontes X modos de aplicação de N significativa. Médias seguidas das mesmas letras nas colunas, não diferem entre si pelo teste de Tukey a $5 \%$. 
Tabela 2. Média de número de fileiras de grãos por espiga (NFG), diâmetro basal do colmo (DBC), teor de $\mathrm{N}$ foliar (N) do milho e leituras SPAD no clorofilômetro (CLOR), em função de fontes e modos de aplicação de $\mathrm{N}$ na cultura do milho irrigado

\begin{tabular}{|c|c|c|c|c|c|c|c|c|}
\hline \multirow{4}{*}{ Tratamentos } & \multicolumn{8}{|c|}{ Ano Agrícola } \\
\hline & 2006/ & $2007 /$ & $2006 /$ & $2007 /$ & $2006 /$ & $2007 /$ & $2006 /$ & $2007 /$ \\
\hline & 2007 & 2008 & 2007 & 2008 & $2007^{*}$ & 2008 & 2007 & 2008 \\
\hline & \multicolumn{2}{|c|}{$\begin{array}{l}\text { NFG } \\
\text { (unid.) }\end{array}$} & \multicolumn{2}{|c|}{$\begin{array}{l}\text { DBC } \\
(\mathrm{mm})\end{array}$} & \multicolumn{2}{|c|}{$\begin{array}{c}\mathrm{N} \\
\left(\mathrm{g} \mathrm{kg}^{-1}\right)\end{array}$} & \multicolumn{2}{|c|}{$\begin{array}{c}\text { CLOR } \\
\text { (SPAD) }\end{array}$} \\
\hline \multicolumn{9}{|l|}{ Fontes } \\
\hline SA & $18 \mathrm{a}$ & $17 \mathrm{a}$ & $21,6 \mathrm{a}$ & 20,5 a & $25,8 a$ & $28,3 \mathrm{a}$ & $56,46 \mathrm{a}$ & $52,70 \mathrm{~b}$ \\
\hline Uréia & $18 \mathrm{a}$ & $17 \mathrm{a}$ & $21,5 \mathrm{a}$ & 20,0 a & $24,5 \mathrm{a}$ & $28,0 \mathrm{a}$ & $55,63 \mathrm{a}$ & $52,76 \mathrm{~b}$ \\
\hline \multicolumn{9}{|l|}{ Modos } \\
\hline $120+0$ & $17 \mathrm{a}$ & $17 \mathrm{a}$ & $22,4 \mathrm{a}$ & $21,3 \mathrm{a}$ & $25,4 \mathrm{a}$ & 29,3 a & $56,62 \mathrm{a}$ & $57,84 \mathrm{a}$ \\
\hline $30+90$ & $18 \mathrm{a}$ & $17 \mathrm{a}$ & $21,1 \mathrm{bc}$ & $20,0 \mathrm{ab}$ & $25,4 \mathrm{a}$ & $28,3 \mathrm{a}$ & $55,98 \mathrm{a}$ & $52,78 b$ \\
\hline $60+60$ & $18 \mathrm{a}$ & $17 \mathrm{a}$ & $21,9 \mathrm{ab}$ & $21,5 \mathrm{a}$ & $25,8 \mathrm{a}$ & $27,5 \mathrm{a}$ & $56,32 \mathrm{a}$ & $53,93 \mathrm{ab}$ \\
\hline $0+120$ & $18 \mathrm{a}$ & $17 \mathrm{a}$ & $20,7 \mathrm{c}$ & $18,7 b$ & $24,0 \mathrm{a}$ & $26,5 \mathrm{a}$ & $54,84 \mathrm{a}$ & $47,93 \mathrm{c}$ \\
\hline CV (\%) & 9,58 & 3,10 & 3,75 & 7,20 & 4,56 & 8,10 & 5,34 & 6,50 \\
\hline
\end{tabular}

* Interação fontes X modos de aplicaçấo de N significativa. Médias seguidas das mesmas letras nas colunas, nâo diferem entre si pelo teste de Tukey a $5 \%$.

as três fontes passam a ter a mesma eficiência no fornecimento de $\mathrm{N}$ às plantas. Com relaçáo ao modo de aplicação de $\mathrm{N}$, esta mesma autora náo verificou efeito sobre o diâmetro do colmo, em virtude do veranico ao qual foram submetidas as plantas após a semeadura, fato que não foi constatado no presente trabalho, em que a água não foi um fator limitante.

Em 2007/2008 ocorreu efeito significativo para fontes e modos de aplicação para leitura de clorofila (Tabela 2). Argenta e Silva (2001) constataram efeitos de doses de $\mathrm{N}$ no índice SPAD, tendo um ajuste linear para a cultura do milho. Neves et al. (2005) verificaram que as leituras SPAD correlacionam-se positivamente com os teores foliares de $\mathrm{N}$ e negativamente com os teores de $\mathrm{S}$.

$\mathrm{Na}$ tabela 3 verifica-se que no ano agrícola de 2006/2007 náo houve efeito significativo entre as fontes e modos de aplicaçáo de $\mathrm{N}$ para todos os componentes da produção e produtividade de grãos de milho. Souza et al. (2001) também observaram que nas épocas de aplicação e de parcelamento do $\mathrm{N}$ náo houve diferenças significativas para a produtividade de grãos. Também, Pauletti e Costa (2000), trabalhando com doses e épocas de aplicaçáo, verificaram que a produtividade de grãos de milho não foi alterada pela aplicaçáo antecipada do $\mathrm{N}$, normalmente utilizado em cobertura no milho. Novamente, a ausência de resposta das fontes e de modos de aplicação de $\mathrm{N}$ deve-se ao fato de logo após a aplicação, ter sido efetuada a irrigação das parcelas, reduzindo drasticamente as perdas por volatilização, principalmente da uréia. Corroboram a estes resultados os observados por Silva et al. (2005) que, ao testarem combinaçóes de épocas de aplicação de nitrogênio na forma de uréia, também não verificaram aumento no número de fileiras de grãos, número de grãos por fileira e massa de mil grãos de milho. Lourente et al. (2007) observaram que as fontes de nitrogênio utilizadas influenciaram apenas o número de grãos por espiga e teor de nitrogênio foliar, resultados diferentes dos avaliados neste trabalho.
Diferente ao que ocorreu em 2006/2007 no ano agrícola seguinte houve efeito significativo das fontes de $\mathrm{N}$ para a massa de gráos por espiga, massa de cem grãos e produtividade de grãos (Tabela 3). Silva et al. (2005b), trabalhando com as doses 0 a $180 \mathrm{~kg} \mathrm{ha}^{-1} \mathrm{de} \mathrm{N}$, observaram aumentos apenas na massa de cem grãos. Fidelis et al. (2007) observaram que doses de $120 \mathrm{~kg} \mathrm{ha}^{-1}$ de $\mathrm{N}$, proporcionaram a melhor produtividade quando avaliaram diferentes cultivares e doses de nitrogênio. Veloso et al. (2006) e Silva et al. (2005a) também constataram aumentos na produtividade com aumento da adubação nitrogenada.

Quanto ao modo de aplicação de $\mathrm{N}$ verificou-se efeito significativo somente para a produtividade de grãos na safra 2007/2008. Pöttker e Wiethölter (2004) observaram que a aplicação de $\mathrm{N}$ na semeadura e em cobertura proporcionou produtividade de milho semelhante às aplicaçóes efetuadas em pré-semeadura e na semeadura. Duete et al. (2009), trabalhando com doses e parcelamentos de nitrogênio na cultura do milho na região de Votuporanga (SP), observaram que a dose de $135 \mathrm{~kg} \mathrm{ha}^{-1}$ de $\mathrm{N}$ parcelada em três vezes foi a que proporcionou maior produtividade. PinHo et al. (2009), estudando três níveis de adubação e nove cultivares de milho, constataram que a utilização de $500 \mathrm{~kg} \mathrm{ha}^{-1}$ da fórmula 8-28-16 na semeadura, mais $300 \mathrm{~kg} \mathrm{ha}^{-1}$ de 30-00-20 na primeira cobertura e $150 \mathrm{~kg} \mathrm{ha}^{-1}$ de uréia na segunda cobertura, proporcionou aumento significativo na produtividade de grãos e na altura das plantas.

Para o número de espigas ha $\mathrm{a}^{-1}$, teor de $\mathrm{N}$ foliar e produtividade de grãos, apesar do efeito não significativo isoladamente para os fatores no ano agrícola de 2006/2007, houve efeito significativo da interaçâoo entre fontes de $\mathrm{N}$ e modos de aplicação (Tabela 4). O número de espigas $\mathrm{ha}^{-1}$ foi significativamente influenciado pela fonte uréia dentro da combinaçấo $120+0 \mathrm{~kg} \mathrm{de} \mathrm{ha}^{-1}$, 
Tabela 3. Médias de número de grãos por fileira (NGF), número de grãos por espiga (NGE), massa de grãos por espiga (MGE), massa de cem grãos (M100) e produtividade de grãos (PROD) de milho, em função de fontes e modos de aplicação de $\mathrm{N}$ na cultura do milho irrigado

\begin{tabular}{|c|c|c|c|c|c|c|c|c|c|c|}
\hline \multirow{3}{*}{ Tratamentos } & \multicolumn{10}{|c|}{ Ano Agrícola } \\
\hline & $\begin{array}{l}2006 / \\
2007\end{array}$ & $\begin{array}{c}2007 / \\
2008\end{array}$ & $\begin{array}{l}2006 / \\
2007\end{array}$ & $\begin{array}{l}2007 / \\
2008\end{array}$ & $\begin{array}{l}2006 / \\
2007\end{array}$ & $\begin{array}{l}2007 / \\
2008\end{array}$ & $\begin{array}{l}2006 / \\
2007\end{array}$ & $\begin{array}{l}2007 / \\
2008\end{array}$ & $\begin{array}{l}2006 / \\
2007^{*}\end{array}$ & $\begin{array}{l}2007 / \\
2008\end{array}$ \\
\hline & \multicolumn{2}{|c|}{$\begin{array}{l}\text { NGF } \\
\text { (unid.) }\end{array}$} & \multicolumn{2}{|c|}{$\begin{array}{c}\text { NGE } \\
\text { (unid.) }\end{array}$} & \multicolumn{2}{|c|}{$\begin{array}{l}\text { MGE } \\
\text { (g) }\end{array}$} & \multicolumn{2}{|c|}{$\begin{array}{l}\text { M100 } \\
\text { (g) }\end{array}$} & \multicolumn{2}{|c|}{$\begin{array}{l}\text { PROD } \\
\left(\text { kg ha }^{-1}\right)\end{array}$} \\
\hline \multicolumn{11}{|l|}{ Fontes } \\
\hline SNA+DMPP & $35,8 \mathrm{a}$ & $36,0 \mathrm{a}$ & $658 \mathrm{a}$ & $619 a$ & 190,8 a & $191,25 a$ & $32,67 \mathrm{a}$ & $34,75 \mathrm{a}$ & $9944 a$ & $9.719 a b$ \\
\hline SA & $36,4 \mathrm{a}$ & $35,4 \mathrm{a}$ & $667 \mathrm{a}$ & $612 \mathrm{a}$ & $192,1 \mathrm{a}$ & $186,92 a b$ & $32,09 \mathrm{a}$ & $34,15 a b$ & $9855 \mathrm{a}$ & $9.903 \mathrm{a}$ \\
\hline Uréia & $36,5 \mathrm{a}$ & 36,0 a & $664 a$ & $624 a$ & 190,9 a & 177,75 b & $32,50 \mathrm{a}$ & 33,44 b & $9634 \mathrm{a}$ & $9.126 b$ \\
\hline \multicolumn{11}{|l|}{ Modos } \\
\hline $120+0$ & $34,6 \mathrm{a}$ & $35,3 \mathrm{a}$ & $663 \mathrm{a}$ & $607 \mathrm{a}$ & $188,7 \mathrm{a}$ & $188,02 \mathrm{a}$ & $32,50 \mathrm{a}$ & $34,82 \mathrm{a}$ & $9681 \mathrm{a}$ & $9.998 \mathrm{a}$ \\
\hline $30+90$ & $37,1 \mathrm{a}$ & $35,1 \mathrm{a}$ & $654 a$ & $610 a$ & $191,5 \mathrm{a}$ & $184,61 \mathrm{a}$ & $32,52 \mathrm{a}$ & $33,63 \mathrm{a}$ & $9694 \mathrm{a}$ & $9.663 a b$ \\
\hline $60+60$ & $37,6 \mathrm{a}$ & $36,8 \mathrm{a}$ & $670 \mathrm{a}$ & $631 \mathrm{a}$ & $191,7 \mathrm{a}$ & $186,29 a$ & $31,82 \mathrm{a}$ & $34,13 a$ & $9810 \mathrm{a}$ & $10.048 \mathrm{a}$ \\
\hline $90+30$ & 35,9 a & 35,9 a & $682 \mathrm{a}$ & $632 a$ & $191,7 \mathrm{a}$ & $188,96 \mathrm{a}$ & $32,33 \mathrm{a}$ & $33,98 \mathrm{a}$ & $9863 \mathrm{a}$ & $9.596 \mathrm{ab}$ \\
\hline $0+120$ & $36,0 \mathrm{a}$ & $35,9 \mathrm{a}$ & $647 \mathrm{a}$ & $612 \mathrm{a}$ & 192,9 a & $178,64 a$ & $32,94 \mathrm{a}$ & $34,00 \mathrm{a}$ & $10008 \mathrm{a}$ & 9.009 b \\
\hline CV (\%) & 8,40 & 7,30 & 11,77 & 7,90 & 5,39 & 7,90 & 4,29 & 4,50 & 7,37 & 8,40 \\
\hline
\end{tabular}

* Interação fontes X modos de aplicação de N significativa. Médias seguidas das mesmas letras nas colunas, não diferem entre si pelo teste de Tukey a $5 \%$.

Tabela 4. Desdobramento da interação significativa entre fontes e modos de aplicação de $\mathrm{N}$ para número de espigas ha-1 $(\mathrm{NE})$, teor de $\mathrm{N}$ foliar (N) e produtividade de grãos (PROD) na cultura do milho irrigado no ano agrícola 2006/2007

\begin{tabular}{|c|c|c|c|}
\hline \multirow{2}{*}{ Modos } & \multicolumn{3}{|c|}{ Fontes } \\
\hline & SNA+DMPP & SA & Uréia \\
\hline \multicolumn{4}{|c|}{ Número de espigas ha ${ }^{-1}$} \\
\hline $120+0$ & $54.444 \mathrm{aA}$ & $55.555 \mathrm{aA}$ & 44.444 bB \\
\hline $30+90$ & $52.222 \mathrm{aA}$ & $48.889 \mathrm{aA}$ & $51.111 \mathrm{abA}$ \\
\hline $60+60$ & $52.222 \mathrm{aA}$ & $50.000 \mathrm{aA}$ & $51.667 \mathrm{abA}$ \\
\hline $90+30$ & $51.667 \mathrm{aA}$ & $52.778 \mathrm{aA}$ & $50.000 \mathrm{abA}$ \\
\hline $0+120$ & $50.556 \mathrm{aA}$ & $50.000 \mathrm{aA}$ & $55.555 \mathrm{aA}$ \\
\hline \multicolumn{4}{|c|}{ Teor de $\mathrm{N}\left(\mathrm{g} \mathrm{kg}^{-1}\right)$} \\
\hline $120+0$ & $27,0 \mathrm{aA}$ & 25,3 aAB & 23,7 bB \\
\hline $30+90$ & 25,4 aA & $25,7 \mathrm{aA}$ & $25,2 \mathrm{abA}$ \\
\hline $60+60$ & 25,7 aA & $26,3 \mathrm{aA}$ & $25,5 \mathrm{abA}$ \\
\hline $90+30$ & 25,6 aA & $26,1 \mathrm{aA}$ & 26,9 aA \\
\hline $0+120$ & 25,7 aA & 25,3 aA & $27,1 \mathrm{aA}$ \\
\hline \multicolumn{4}{|c|}{ Produtividade de grãos $\left(\mathrm{kg} \mathrm{ha}^{-1}\right)$} \\
\hline $120+0$ & $9.858 \mathrm{aA}$ & $10.808 \mathrm{aA}$ & 8.375 bB \\
\hline $30+90$ & $10.156 \mathrm{aA}$ & 9.183 bA & $9.742 \mathrm{abA}$ \\
\hline $60+60$ & $9.814 \mathrm{aA}$ & $9.886 a b A$ & $9.731 \mathrm{abA}$ \\
\hline $90+30$ & $10.097 \mathrm{aA}$ & $9.889 \mathrm{abA}$ & $9.603 \mathrm{abA}$ \\
\hline $0+120$ & $9.795 \mathrm{aA}$ & $9.511 \mathrm{abA}$ & $10.719 \mathrm{aA}$ \\
\hline
\end{tabular}

Médias seguidas das mesmas letras maiúsculas nas linhas e minúsculas nas colunas, náo diferem entre si pelo teste de Tukey a 5\%.

ou seja, com aplicação total de $\mathrm{N}$ na semeadura, com uréia como fonte, houve redução do número de espigas e conseqüentemente da produtividade de grãos de milho (Tabela 4). Dentro dos modos de aplicaçáo em cada fonte de $\mathrm{N}$, também a adubação em dose total na semeadura com uréia proporcionou redução no número de espigas, teor de $\mathrm{N}$ foliar e reflexo direto na menor produtividade. Provavelmente, pelas intensas chuvas ocorridas durante o período pós-semeadura, a fonte de uréia pode ter proporcionado maiores perdas por desnitrificação e/ou lixiviação, faltando $\mathrm{N}$ para a planta em estádio inicial do seu desenvolvimento, quando são definidos os componentes de produção número de espigas por planta e número de fileiras de grãos por espiga, uma vez que a populaçấo final de plantas e os demais componentes da produção não foram influenciados pelos tratamentos. Tais resultados corroboram os de Basso e Ceretta (2000) ao afirmar que a aplicação de $\mathrm{N}$ em uma única época

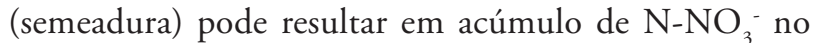
solo nos estádios iniciais de desenvolvimento de milho, passíveis de lixiviação, pois a demanda total da planta é pequena na fase inicial de desenvolvimento.

\section{CONCLUSÃO}

A aplicação do sulfonitrato de amônio + inibidor de nitrificação não proporciona diferença em relação ao sulfato de amônio quantos aos componentes da produção do milho cultivado no verão, independentemente da época de aplicação. A aplicaçáo de $120 \mathrm{~kg} \mathrm{ha}^{-1}$ de nitrogênio usando a uréia em aplicação única no estádio de oito folhas na cultura do milho e em períodos com alta precipitação pluvial afeta negativamente os teores foliares de $\mathrm{N}$ no milho e resulta em menor produtividade de grãos em relação à aplicação da mesma dose na semeadura.

\section{REFERÊNCIAS}

AMADO, T.J.C.; MIELNICZUK, J.; FERNANDES, S.B.V. Leguminosas e adubação mineral como fonte de nitrogênio para o milho em sistemas de preparo do solo. Revista Brasileira de Ciência do Solo, v.24, p.179-189, 2000.

AMADO, T.J.C.; MIELNICZUK, J.; AITA, C. Recomendação de adubação nitrogenada para o milho no RS e SC adaptada ao uso de culturas de cobertura do solo, sob sistema plantio direto. Revista Brasileira de Ciência do Solo, v.26, p.241-248, 2002. 
ARGENTA, G.; SILVA, P.R.F. Adubação nitrogenada em milho implantado em semeadura direta após aveia-preta. Ciência Rural, v.31, p.715-722, 2001

ARGENTA. G.; SILVA, P.R.F.; SANGOI, L. Arranjo de plantas em milho: análise do estado-da-arte. Ciência Rural, v.31, p.1075-1084, 2001.

BASSO, C.J.; CERETTA, C.A. Manejo do nitrogênio no milho em sucessão a plantas de cobertura de solo, sob plantio direto. Revista Brasileira de Ciência do Solo, v.24, p.905-915, 2000.

BORTOLINI, C.G.; SILVA, P.R.F; ARGENTA, G.; FORSTHOFER, E.L. Rendimento de grãos de milho cultivado após aveia-preta em respostas a adubação nitrogenada e regime hídrico. Pesquisa Agropecuária Brasileira, v.36, p.1101-1106, 2001.

CASAGRANDE, J.R.R.; FORNASIERI FILHO, D. Adubação nitrogenada na cultura do milho safrinha. Pesquisa Agropecuária Brasileira, v.37, p.33-40, 2002.

DUETE, R.R.C.; MURAOKA, T.; SILVA, E.C.; TREVELIN, P.C.O.; AMBROSANO, E.J. Manejo da adubação nitrogenada e utilização do nitrogênio (15N) pelo milho em Latossolo Vermelho. Revista Brasileira de Ciência do Solo, v.32, p.161-171, 2008.

DUETE, R.R.C.; MURAOKA, T.; SILVA, E.C.; TREVELIN, P.C.O.; AMBROSANO, E.J. Viabilidade econômica de doses e parcelamentos da adubaçáo nitrogenada na cultura do milho em Latossolo Vermelho Eutrófico. Acta Scientiarum Agronomy, v.31, p.175-181, 2009.

FERNANDES, F.C.S.; BUZETTI, S.; ARF, O.; ANDRADE, J.A.C. Doses, eficiência e uso de nitrogênio por seis cultivares de milho. Revista Brasileira de Milho e Sorgo, v.4, p.195-204, 2005.

FIDELIS, R.R.; MIRANDA, G.V.; SANTOS, I.C.; GALVÃO, J.C.C.; PELUZIO, J.M.; LIMA, S.O. Fontes de germoplasma de milho para estresse de baixo nitrogênio. Pesquisa Agropecuária Tropical, v.37, p.147-153, 2007.

LOURENE, E.R.P.; ONTOCELLI, R.; SOUZA, L.C.F.; GONÇALVES, M.C.; MARCHETTI, M.E.; RODRIGUES, E.T. Culturas antecessoras, doses e fontes de nitrogênio nos componentes de produçáo do milho. Acta Scientiarum Agronomy, v.29, p.55-61, 2007.

MEIRA, F.A.; BUZETTI, S.; ANDREOTTI, M.; ARF, O.; SÁ, M.E.; ANDRADE, J.A.C. Fontes e épocas de aplicação do nitrogênio na cultura do milho irrigado. Semina Ciências Agrárias, v.30, p.275-284, 2009.

NEVES, O.S.C.; CARVALHO, J.G.; MARTINS, F.A.D.; PÁDUA, T.R.P.; PINHO, P.J. Uso do SPAD-502 na avaliação dos teores foliares de clorofila, nitrogênio, enxofre, ferro e manganês do algodoeiro herbáceo. Pesquisa Agropecuária Brasileira, v.40, p.517-521, 2005.
OLIVEIRA, J.M.S.; CAIRES, E.F. Adubação nitrogenada em cobertura para o milho cultivado após aveia preta no sistema plantio direto. Acta Scientiarum Agronomy, v.25, p.351-357, 2003.

PAULETTI, V.; COSTA, L.C. Época de aplicação de nitrogênio no milho cultivado em sucessão à aveia preta no sistema plantio direto. Ciência Rural, v.30, p.599-603, 2000.

PINHO, R.G.V.; RIVERA, A.A.C.; BRITO, A.H.; LIMA, T.G. Avaliação agronômica do cultivo de milho em diferentes níveis de investimento. Ciência e Agrotecnologia, v.33, p.39-46, 2009.

POSSAMAI, J.M.; SOUZA, C.M.; GALVÃO, J.C. Sistemas de preparo do solo para o cultivo do milho safrinha. Bragantia, v.60, p.79-82, 2001.

PÖTTKER, D.; WIETHÖLTER, S. Épocas e métodos de aplicação de nitrogênio em milho cultivado no sistema plantio direto. Ciência Rural, v.34, p.1015-1020, 2004.

RAIJ, B. van.; ANDRADE, J.C.; CANTARELLA, H.; QUAGGIO, J.A. Análise química para avaliação da fertilidade de solos tropicais. Campinas: Instituto Agronômico, 2001. 284p.

RAIJ, B. van.; CANTARELLA, H.; GUAGGIO, J.A.; FURLANI, A.M.C. Recomendaçôes de adubação e calagem para o Estado de São Paulo. 2.ed. Campinas: Instituto Agronômico, 1997. 285p. (Boletim técnico, 100)

SILVA, E.C.; FERREIRA, S.M.; SILVA, G.P.; ASSIS, R.L.; GUIMARÃES, G.L. Épocas e formas de aplicação de nitrogênio no milho sob plantio direto em solo de cerrado. Revista Brasileira de Ciência do Solo, v.29, p.725-733, 2005a.

SILVA, E.C.; BUZETTI, S.; GUIMARÃES, G.L.; LAZARINI, E.; SÁ, M.E. Doses e épocas de aplicação de nitrogênio na cultura do milho em plantio direto sobre Latossolo Vermelho. Revista Brasileira de Ciência do Solo, v.29, p.353-362, 2005 b.

SOUZA,A.C.; CARVALHO, J.G.; PINHO, R.G.V.; CARVALHO, M.L.M. Parcelamento e época de aplicaçáo de nitrogênio e seus efeitos em características agronômicas do milho. Ciência e Agrotecnologia, v.25, p.321-329, 2001.

VELOSO, M.E.C.; DUARTE, S.N.; DOURADO NETO, D.; MIRANDA, J.H.; SILVA, E.C.; SOUSA, V.F. Doses de nitrogênio na cultura do milho, em solos de várzea, sob sistema de drenagem subterrânea. Revista Brasileira de Milho e Sorgo, v.5, p.382-394, 2006.

VITTI, G.C.; TAVARES, J.E.; LUZ, P.H.C.; FAVARIN, J.L.; COSTA, M.C.G. Influência da mistura de sulfato de amônio com uréia sobre a volatilização de nitrogênio amoniacal. Revista Brasileira de Ciência do Solo, v.26, p.663-671, 2002. 